\title{
A Preliminary Transcriptomic Approach to Elucidate Post Harvest Ripening of Plum Fruit
}

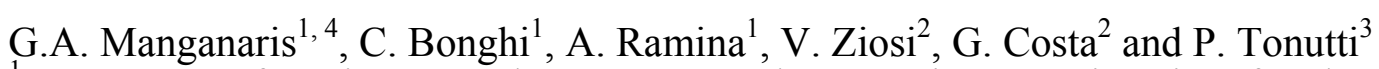

${ }^{1}$ Department of Environmental Agronomy and Crop Science, University of Padova, viale dell'Università 16, 35020 Legnaro (Padova), Italy

${ }^{2}$ Department of Fruit Trees and Woody Plant Sciences, University of Bologna, Via Fanin 46, 40127, Bologna, Italy

${ }^{3}$ Scuola Superiore Sant' Anna, Piazza Martiri della Libertà 33, 56127 Pisa, Italy

${ }^{4}$ Current Address: Cyprus University of Technology, Department of Agricultural Sciences, Biotechnology \& Food Science, P.O. Box 50329, 3603, Lemessos, Cyprus

Keywords: genomics tools, microarray, oligonucleotide hybridization, climacteric, suppressed-climacteric, Rosaceae, Prunus salicina, Prunus persica

\begin{abstract}
The aim of the present study was to dissect common and/or diverse mechanisms regulating plum (Prunus salicina) fruit ripening in genotypes characterized by different patterns of ethylene production. Fruit of an ethylenesuppressed cultivar ('Shiro') and a cultivar characterized by the typical increase of ethylene production during fruit ripening ('Santa Rosa') were harvested at commercial maturity stage and allowed to further ripen at room temperature $\left(23^{\circ} \mathrm{C}\right)$ up to 4 days. While non-detectable amounts of ethylene were recorded in 'Shiro' fruit, a typical climacteric behavior was observed in 'Santa Rosa' plums. For comparative purposes, the peach microarray $\mu$ PEACH 1.0 containing 4,806 oligonucleotides corresponding to an equal number of genes expressed in peach fruit was employed for transcript profiling during postharvest ripening of both cultivars. Intriguingly, transcript levels of genes involved in ethylene biosynthesis, primarily 1aminocyclopropane-1-carboxylate synthase, appeared to increase during the progress of 'Shiro' fruit ripening, following the same pattern as in 'Santa Rosa' plums. These data suggest that an induction of the ethylene biosynthetic pathway is present also in plum cultivars in which the burst of ethylene is not detectable. Expression levels of other genes implicated in auxin metabolism, antioxidant system and stress response followed the same pattern in both cultivars. Overall, this preliminary transcriptomic approach tried to elucidate the flow of events that accompany postharvest ripening of plum cultivars with diverse properties in relation to ethylene evolution.
\end{abstract}

\section{INTRODUCTION}

Transcript profiling methods are increasingly used to understand the biological basis of growth and development, and in the case of fruits, of their quality (reviewed in Bonghi and Trainotti, 2006). Microarray technology is suitable for large scale trancriptomic analyses, through the simultaneous monitoring of many genes in a single experiment, and it can be utilized for gene discovery in species where few resources are available. In the case of stone fruits, an oligonucleotide peach microarray ( $\mu$ PEACH1.0) was recently made available (ESTree consortium, 2005) and has been applied to study the transition from pre-climacteric to climacteric stage (Trainotti et al., 2006), to elucidate the role of auxin and jasmonate in the peach fruit ripening syndrome (Trainotti et al., 2007; Ziosi et al., 2008) and describe, at molecular level, the effects of the antagonist of ethylene action, 1-methylcyclopropene (1-MCP) in ripening peaches or nectarines (Ziliotto et al., 2008). In addition, taking into account the high degree of sequence conservation among the Prunus species, this microarray has been applied to monitor transcript profiling throughout apricot fruit development (Manganaris et al., 2009). Using this comparative approach, isolation of genes related to traits of agronomic interest, comparison among Prunus species with common and/or divergent mechanisms of fruit 
growth and ripening pattern, as well as selection of new candidate genes for further analyses can be performed.

Plum (Prunus salicina Lindell) fruits show great diversity in terms of size, pigment content, rate of ripening and post-harvest decay. Plum is classified as a climacteric fruit; however, two distinct types of ripening behaviour have been observed for several cultivars, and plums are categorised in two groups: climacteric and nonclimacteric (or suppressed-climacteric) (Abdi et al., 1997, 1998; Martinez-Romero et al., 2003). The latter is characterised by non-detectable amounts of ethylene production during fruit ripening; even though the suppressed climacteric cultivars were shown to be sensitive to exogenous ethylene and its analogues (Abdi et al., 1997). Such differences regarding ethylene production within cultivars of the same species have been also reported for peaches (Tatsuki et al., 2006; Begheldo et al., 2008) and pears (Yamane et al., 2007).

Although plum is an attractive species to identify genes controlling the development of quality traits; up to now it is largely uncharacterized. Therefore, the aim of the present study was to investigate the gene regulation during plum fruit postharvest ripening by using the peach microarray ( $\mu$ PEACH1.0), the unique high-throughput transcriptomic tool so far available for stone fruits. For this purpose, we compared plum cultivars with diverse climacteric pattern in order to monitor transcript levels of genes related to ethylene metabolism, auxin regulation, stress/defense system and overall expression levels of genes implicated in the transcription/translation machinery.

\section{MATERIALS AND METHODS}

\section{Fruit Material - Quality Measurements}

Plum fruit ('Shiro' and 'Santa Rosa') were collected in 2007 at commercial maturity stage in an orchard near Vignola (Modena, Italy). After harvest (d0), fruit were transferred in a growth chamber and kept at $23^{\circ} \mathrm{C}$ up to 4 days (d4). On d0 and $\mathrm{d} 4$ mesocarp from a pool of 10 fruit was frozen in liquid nitrogen and kept at $-80^{\circ} \mathrm{C}$ until needed. On the same days ethylene production and flesh firmness (FF) were assessed on 10 fruit per cultivar as described by Bregoli and co-workers (2002).

\section{RNA Extraction and Microarray Experiments}

Microarray experiments were carried out during the transition of fruit of each cultivar from harvest (d0) to 4 days of shelf life (d4). Total RNA-DNA free (20 $\mu \mathrm{g})$, extracted as described by Bonghi and co-workers (1998) was converted into target cDNA by reverse transcription using the SuperScript ${ }^{\mathrm{TM}}$ Indirect $\mathrm{cDNA}$ Labeling System (Invitrogen, USA) following manufacturer instructions. The amino-modified cDNA was coupled to a monoreactive N-hydroxysuccinimide (NHS)-ester fluorescent dye: the greenfluorescent cyanine3 (Cy3) and the red-fluorescent cyanine5 (Cy5) (Amersham Biosciences, UK). The resulting fluorescently labelled cDNA targets were hybridized to the oligonucleotide peach microarray $\mu \mathrm{PEACH}$ 1.0. The features, preparation and hybridization protocols of the peach microarray $\mu \mathrm{PEACH} 1.0$ are described in Trainotti et al. (2006).

The microarrays were scanned with a two-channel confocal microarray scanner (ScanArray ${ }^{\circledR}$ Lite, Perkin-Elmer) using its dedicated software (ScanArray Express 3.0.0., Perkin-Elmer) and two separate 16-bit TIFF images were produced. The images were then processed with the TIGR Spotfinder 2.2.3 software using the Otsu algorithm. Raw data were imported to Genespring Software demo (Agilent Tech., USA) and Locally Weighted Regression Scatter Plot Smoothing (LOWESS) approach has been used to normalize and transform the expression ratios. After normalization, the ratios were transformed to their $\log _{2}$ values. Genes showing $\log _{2}$ ratio higher than 1.0 are characterised as up-regulated, and those with $\log _{2}$ ratio lower than -1.0 are characterised as down-regulated. 


\section{RESULTS AND DISCUSSION}

At harvest FF of Santa Rosa' and 'Shiro' plums was $8.5 \pm 1.6$ and $7.5 \pm 0.5 \mathrm{~N}$, respectively; after 4 days of shelf life FF declined to $2.0 \pm 0.5$ ('Santa Rosa') and $1.0 \pm 0.24$ $\mathrm{N}$ ('Shiro'). However, it should be pointed out that in spite of the lower tissue firmness the 'Shiro' fruit at day 4 were characterised by a soft-juicy texture, while 'Santa Rosa' fruit were commercially unacceptable. In addition, the penetrometer is not always adequate to measure the progress of the changes in texture, particularly as the fruit become very soft (Orr and Brady, 1993). In 'Santa Rosa', ethylene production increased from 7.4 $\pm 0.9 \mathrm{nl} \mathrm{L}^{-1} \mathrm{~h}^{-1} \mathrm{~g}^{-1} \mathrm{FW}$ (d0) to $59.5 \pm 3.5 \mathrm{nl} \mathrm{L}^{-1} \mathrm{~h}^{-1} \mathrm{~g}^{-1} \mathrm{FW}$ (d4), while, in 'Shiro', ethylene production remained undetectable throughout the experimental period.

Significant Analysis for Microarrays (SAM analysis) generated a set of 956 genes in 'Santa Rosa' plums during the transition from d0 to d4. Among them, 157 were upregulated, 628 were unaffected, while 101 were repressed. Regarding 'Shiro' plums, SAM analysis generated positive results for 637 genes. Among them, 103 were induced, 474 remained unaffected and 60 were repressed. The current study has focused on genes responsive to hormone signals (ethylene, auxin), to abiotic and biotic stress and those encoding antioxidant enzymes.

Transcript levels of 1-aminocyclopropane-1-carboxylate (ACC) synthase were highly up-regulated in both cultivars (Fig. 1a). ACC concentrations have been reported to be similar in both fruit types (Abdi et al., 1998), suggesting that the suppressedclimacteric phenotype is the result of an impaired ability of the fruit to convert ACC into ethylene. An up-regulation of an ethylene response factor (ERF2) was also monitored in both cultivars (Fig. 1a). ERF genes act in the last step of the ethylene signaling pathway but can also respond to other factors and stress conditions. In apples, low ethylene producing cultivars show lower MdERFs expression than those characterized by higher ethylene production (Wang et al., 2007). This seems to be also the case in plums; in fact, El-Sharkawy et al. (2007) hypothesized that the absence of transcripts of Ps-ERF1 and the reduced expression of the ethylene receptor Ps-ERS1 may result in the suppressedclimacteric behaviour at ripening. Expression data concerning the ethylene receptor ETR2 cannot give any clues (Fig. 1a). Trainotti and co-workers (2005) studied the receptors mostly expressed in ripening strawberries and suggested that in this non-climacteric fruit even the little ethylene produced might be sufficient to trigger ripening. A holistic approach in ethylene receptors in order to elucidate the ripening syndrome in the examined cultivars is needed.

Members of AUX/IAA family, encoding proteins actively involved in the auxin signaling network, are up-regulated during ripening of peach (Trainotti et al., 2007) and apricot (Manganaris et al., 2009). In our study, an increase of IAA 16 transcript level was observed in ripe fruit of both cultivars, while other auxin regulated proteins remained unaffected (Fig. 1b). These results suggest that in stone fruits the action of auxin could be regulated by a common set of genes. However, the pattern of such genes may differ during postharvest ripening compared to the maturation process (on-tree ripening).

As observed in other species (Giovannoni, 2004), in both cultivars an expression increase of genes encoding pathogenesis related proteins (thaumatin, harpin inducing protein) has been detected. A slight decrease in transcript amount of two heat shock proteins (HSPs) in ripening plum fruit has been monitored (Fig. 2a). In apricot fruit an upregulation of HSP genes during on-tree ripening has been reported (Manganaris et al., 2009); whether this increase is species specific or related to the ripening on and off-tree has to be proved.

Genes encoding antioxidant enzymes (ascorbate peroxidase (APX), peroxidase (POD), catalase (CAT)) showed similar patterns in both cultivars (Fig. 2b). It is well documented that, in many fleshy fruits, a gradual loss in the ability to neutralize free radicals occurs with the progression of ripening and the lipid oxidation is actually paralleled by the peroxide levels. However, no further information about the plum transcriptomic profiling or the antioxidant enzymes specific activity is available. 


\section{CONCLUSIONS}

Results indicated that peach gene chip ( $\mu$ PEACH 1.0) can be successfully applied in related, yet phenotypically distinct, species like plums, as recently reported also for apricot fruit (Manganaris et al., 2009). Future perspectives should include transcriptomic studies in which the effect of ethylene antagonists, such as 1-methylcyclopropene, should be assessed. In addition, microarray analysis should be carried out throughout the fruit development to isolate genes specifically involved in the regulation of phase transition.

\section{ACKNOWLEDGEMENTS}

This research has been funded by the Italian Ministry of Research and University (MIUR), Cofin project no. 200672159 coordinated by PT. GAM is a recipient of an E.U. Marie Curie individual fellowship (Grant MEIF-CT-2006-038997).

\section{Literature Cited}

Abdi, N., Holford, P., McGlasson, W.B. and Mizrahi, Y., 1997. Ripening behaviour and responses to propylene in four cultivars of Japanese type plums. Postharvest Biol. Technol. 12:21-34.

Abdi, N., McGlasson, W.B., Holford, P., Williams, M. and Mizrahi, Y. 1998. Responses of climacteric and suppressed-climacteric plums to treatment with propylene and 1methylcyclopropene. Postharvest Biol. Technol.14:29-39.

Begheldo, M., Manganaris, G.A., Bonghi, C. and Tonutti, P. 2008. Different postharvest conditions modulate ripening and ethylene biosynthetic and signal transduction pathways in Stony Hard peaches. Postharvest Biol. Technol. 48:84-91.

Bonghi, C., Ferrarese, L., Ruperti, B., Tonutti, P. and Ramina, A. 1998. Endo-beta-1,4glucanases are involved in peach fruit growth and ripening, and regulated by ethylene. Physiol. Plant.102:346-352.

Bonghi, C. and Trainotti, L. 2006. Genomic tools for a better understanding of the fruit ripening process. Stewart Postharvest Review 2:1-10.

Bregoli, A.M., Scaramagli, S., Costa, G., Sabatini, E., Ziosi, V., Biondi, S. and Torrigiani, P. 2002. Peach (Prunus persica) fruit ripening: aminoethoxyvinylglycine (AVG) and exogenous polyamines affect ethylene emission and flesh firmness. Physiol. Plant. 114:472-481.

El-Sharkawy, I., Kim, W.S., El-Kereamy, A., Jayasankar, S., Svircev, A.M. and Brown, D.C.W. 2007. Isolation and characterization of four ethylene signal transduction elements in plums (Prunus salicina L.). J. Exp. Bot. 58:3631-3643.

ESTree Consortium. 2005. Development of an oligo-based microarray ( $\mu$ PEACH 1.0) for genomics studies in peach fruit. Acta Hort. 682:263-268.

Giovannoni, J. 2004 Genetic regulation of fruit development and ripening. Plant Cell 16(suppl.):S170-S180.

Manganaris, G.A., Ziliotto, F. Rasori, A., Bonghi, C., Ramina, A., Banfi, R., Geuna, F., Bassi, D. and Tonutti P. 2009. Gene expression profile during apricot fruit growth, using a peach microarray. Acta Hort. 817:113-118.

Martinez-Romero, D., Dupille, E., Guillen, F., Valverde, J.M., Serrano, M. and Valero, D. 2003. 1-Methylcyclopropene increases storability and shelf life in climacteric and nonclimacteric plums. J. Agric. Food Chem. 51:4680-4686.

Orr, G. and Brady, C. 1993. Relationship of endopolygalacturonase activity to fruit softening in a freestone peach. Postharvest Biol. Technol. 3:121-130.

Tatsuki, M., Haji, T. and Yamaguchi, M. 2006. The involvement of 1aminocyclopropane-1-carboxylic acid synthase isogene, Pp-ACS1, in peach fruit softening. J. Exp. Bot. 57:1281-1289.

Trainotti, L., Pavanello, A. and Casadoro, G. 2005. Different ethylene receptors show an increased expression during the ripening of strawberries: does such an increment imply a role for ethylene in the ripening of these non-climacteric fruits? J. Exp. Bot. 56:2037-2046.

Trainotti, L., Bonghi, C., Ziliotto, F., Zanin, D., Rasori, A., Casadoro, G. Ramina, A. and 
Tonutti, P. 2006. The use of microarray $\mu$ PEACH1.0 to investigate transcriptome changes during transition from pre-climacteric to climacteric phase in peach fruit. Plant Sci. 170:606-613.

Trainotti, L., Tadiello, A. and Casadoro G. 2007. The involvement of auxin in the ripening of climacteric fruits comes of age: The hormone plays a role of its own and has an intense interplay with ethylene in ripening peaches. J. Exp. Bot. 58:3299-3308.

Wang, A., Tan, D., Takahashi, A., Li, T.Z. and Harada, T. 2007. MdERFs, two ethyleneresponse factors involved in apple fruit ripening. J. Exp. Bot. 58:3743-3748.

Yamane, M., Abe, D., Yasui, S., Yokotani, N., Kimata, W., Ushijima, K., Nakano, R., Kubo, Y. and Inaba, A. 2007. Differential expression of ethylene biosynthetic genes in climacteric and non-climacteric Chinese pear fruit. Postharvest Biol. Technol. 44:220 227.

Ziliotto, F., Begheldo, M., Rasori, A., Bonghi, C. and Tonutti, P. 2008. Transcriptome profiling of ripening nectarine (Prunus persica L. Batsch) fruit treated with 1-MCP. J. Exp. Bot. 59:2781-2791.

Ziosi, V., Bonghi, C., Bregoli, A.M., Trainotti, L., Biondi, S., Sutthiwal, S., Kondo, S., Costa, G. and Torrigiani, P. 2008. Jasmonate-induced transcriptional changes suggest a negative interference with the ripening syndrome in peach fruit. J. Exp. Bot. 59:563573. 

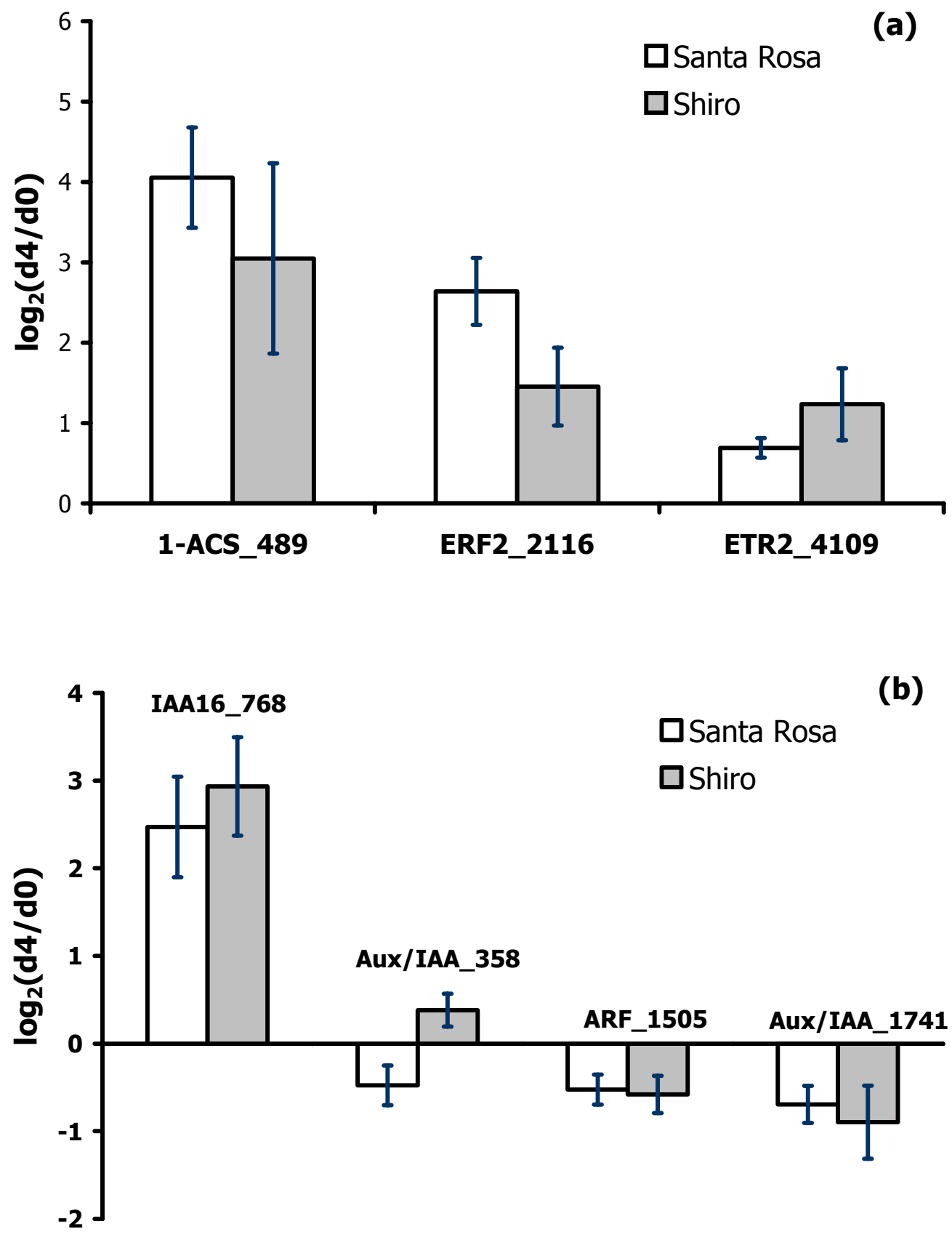

Fig. 1. Modulation of gene expression, measured by means of the $\mu$ PEACH1.0 microarray, during the transition of 'Santa Rosa' and 'Shiro' plum fruit from harvest (d0) to 4 days shelf life (d4). Numbers after gene acronyms indicate the peach contig name. Bars correspond to \pm SD of the means. ACS: 1aminocyclopropane-1-carboxylate synthase, ERF: ethylene response factor, ETR: ethylene receptor, ARF: auxin response factor. 

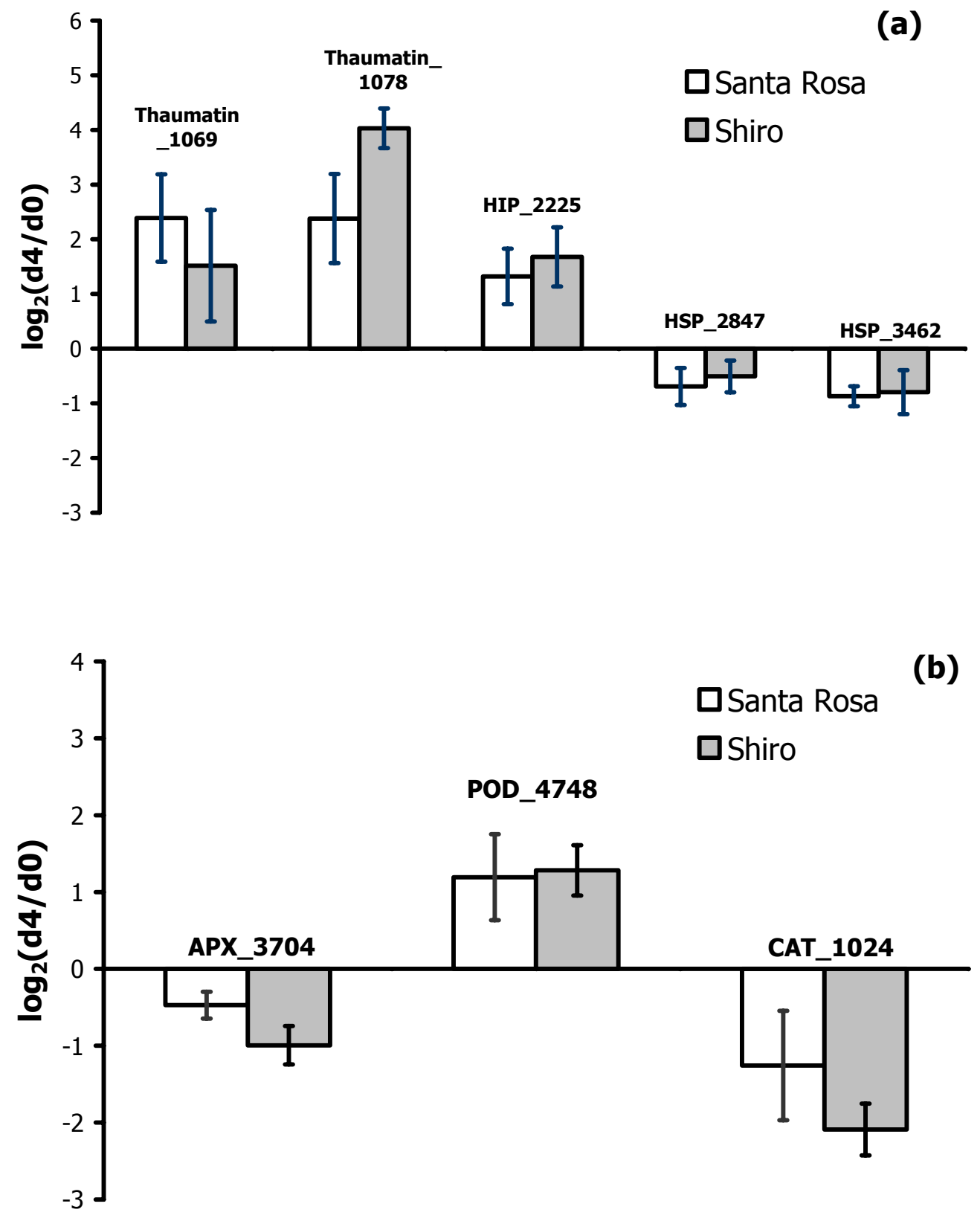

Fig. 2. Modulation of gene expression, measured by means of the $\mu$ PEACH1.0 microarray, during the transition of 'Santa Rosa' and 'Shiro' plum fruit from harvest (d0) to 4 days shelf life (d4). Numbers after gene acronyms indicate the peach contig name. Bars correspond to \pm SD of the means. HIP: Harpin inducing protein, HSP: heat shock protein, APX: ascorbate peroxidase, POD: peroxidase, CAT: catalase. 
